\title{
Responses to carotid sinus stimulation before and after propranolol
}

\author{
HANS BERGLUND, „ MÅTEN ROSENQVIST, „SAMIA BOUKTER, * \\ STURE BEVEGÅR, K OLOF EDHAG* \\ From the $\star$ Department of Medicine, Cardiac Division, Karolinska Institute, Huddinge Hospital and the \\ Department of Clinical Physiology, Karolinska Institute, Södersjukhuset, Stockholm, Sweden
}

SUMMARY The response to carotid sinus stimulation was studied in nine elderly men (mean age्छे 67) with no history of cardiac disease, dizziness, or syncope. The response to manual carotid sinus pressure (during one of two studies) was positive (an RR interval of $>3 \mathrm{~s}$ ) in three men. But seveg men showed positive responses after intravenous propranolol $(0 \cdot 1 \mathrm{mg} / \mathrm{kg})$. Similarly, the RR interval was lengthened by $>10 \mathrm{~ms} / \mathrm{mm} \mathrm{Hg}$ in two men during neck suction. Neck suction produced a positive result in four men after intravenous propranolol.

The detection of hypersensitivity of the carotid sinus in a high proportion of apparently health men, especially during $\beta$ blockade, suggests that an abnormal response to carotid sinus massage may not be a reliable indicator for pacemaker treatment.

Since Weiss and Baker in 1933 described hypersensitivity of the carotid sinus as a cause of syncope ${ }^{1}$ there has been considerable controversy about the importance of this sign. ${ }^{2}$ Even though carotid sinus massage is an unphysiological stimulus that is difficult to measure it is widely used in the absence of an easily applied and more scientific method. Carotid sinus hypersensitivity-that is an $R R$ interval of more than three seconds during carotid sinus massage-in patients with unexplained syncope is often used as an indication for pacemaker treatment. ${ }^{3}$ The combination of unexplained syncope and carotid sinus hypersensitivity is called the carotid sinus syndrome. The results of earlier studies of the response to stimulation of the carotid sinus in healthy older people are conflicting, possibly because they used different techniques. ${ }^{4-7}$

\section{Patients and methods}

We studied nine elderly men (mean (SD) age of 67 (4) years (range 61-71) with no history of cardiac disease, dizziness, or syncope. An extensive noninvasive cardiac evaluation, including physical examination, twelve-lead electrocardiograms, chest

Requests for reprints to Dr Hans Berglund, Department of Medicine, Cardiac Division, Huddinge Hospital, S-141 86 Huddinge, Sweden.

Accepted for publication 31 May 1988 $x$ ray, an exercise test, echocardiography, and routing blood tests, was performed to exclude importan heart disease. In addition, a Doppler investigation of the carotid bifurcation was performed to rule out the possibility of clinically important narrowing of the carotid arteries. All the men were electrocardiogra $\vec{B}$ phically monitored for 24 hours. A tenth, otherwise apparently healthy man, who was found to have spontaneous asymptomatic complete atrioven? tricular block with an RR interval of between $3 \cdot 1$ and $4.2 \mathrm{~s}$, was excluded. Informed consent was obtainea from all the men and the study was approved by the local ethics committee. Table 1 shows the character istics of the patients.

Manual pressure was applied to the carotid sinus for five seconds, three times on each side of the necks without abolishing the ipsilateral temporal arter pulse. The procedure was performed before and after an intravenous injection of propranolol $(0.1 \mathrm{mg} / \mathrm{kg}$ on two occasions at least one month apart with the patient in both the supine position and with a headv up tilt at $60^{\circ}$. Recordings were made between 5 an 40 minutes after the full dose of propranolol had beet given. Manual carotid pressure was applied by the same investigator and the patients were randomle chosen to start the investigation in the supine posin tion or with head up tilting.

At the first investigation a negative pressure of $-40 \mathrm{~mm} \mathrm{Hg}$ was also applied to the front of the necl by a neck suction device; ${ }^{9}$ this was done three times for one minute each time. The instrument that we 
Table 1 Characteristics of elderly men who were tested by carotid sinus massage

\begin{tabular}{|c|c|c|c|c|c|c|c|}
\hline Subject & $\begin{array}{l}\text { Age } \\
(y)\end{array}$ & $\begin{array}{l}\text { Weight } \\
\text { (kg) }\end{array}$ & $\begin{array}{l}\text { Height } \\
(\mathrm{cm})\end{array}$ & $\begin{array}{l}\text { Exercise } \\
\text { test }^{\star}(W)\end{array}$ & $\underset{(\mathrm{mm})}{L V E D d}$ & $\begin{array}{l}R H V \\
\left(m l / m^{2}\right)\end{array}$ & $\begin{array}{l}L T E R \\
(s)\end{array}$ \\
\hline $\begin{array}{l}1 \\
2 \\
3 \\
4 \\
5 \\
6 \\
7 \\
8 \\
9\end{array}$ & $\begin{array}{l}61 \\
60 \\
70 \\
71 \\
67 \\
68 \\
68 \\
65 \\
65\end{array}$ & $\begin{array}{l}78 \\
86 \\
65 \\
77 \\
75 \\
88 \\
73 \\
65 \\
75\end{array}$ & $\begin{array}{l}182 \\
183 \\
178 \\
174 \\
182 \\
182 \\
169 \\
172 \\
172\end{array}$ & $\begin{array}{l}180 \\
218 \\
190 \\
170 \\
192 \\
224 \\
180 \\
260 \\
210\end{array}$ & $\begin{array}{l}44 \\
48 \\
42 \\
42 \\
49 \\
48 \\
48 \\
46 \\
48\end{array}$ & $\begin{array}{l}330 \\
460 \\
450 \\
430 \\
520 \\
410 \\
430 \\
440 \\
480\end{array}$ & $\begin{array}{l}1 \cdot 2 \\
1.4 \\
1 \cdot 1 \\
1 \cdot 3 \\
1 \cdot 1 \\
1 \cdot 3 \\
1.4 \\
1.5 \\
1 \cdot 1\end{array}$ \\
\hline
\end{tabular}

^Bicycle test with a continuous increase in work load of $10 \mathrm{~W} / \mathrm{min}$; LVEDd, left ventricular end diastolic diameter measured by echocardiography; RHV, relative heart volume measured by chest $x$ ray and expressed as $\mathrm{ml} / \mathrm{m}^{2}$ body surface area; ${ }^{8} \mathrm{LTER}$, longest $\mathbf{R R}$ interval on long term echocardiographic recording.

used is a modified version of Eckberg's neck suction device moulded in lead that can be adjusted to fit different people without producing positive pressure near the carotid vessels. ${ }^{10} \mathrm{~A}$ negative pressure of -40 $\mathrm{mm} \mathrm{Hg}$ was achieved within $300 \mathrm{~ms}$. The electrocardiogram was monitored throughout the study and at the first investigation the brachial arterial pressure was recorded on a Siemens Elema Mingograf 81 . The maximum $R R$ intervals seen during manual carotid pressure are reported. A corrected carotid sinus inhibitory time-maximum $R R$ interval minus basic cycle length - was calculated to correct for the underlying heart rate and to allow comparison with the findings during neck suction, and also between head up tilting and the supine position, and between the two occasions. Lengthening of the $R R$ interval during neck suction is given as $\mathrm{ms} / \mathrm{mm} \mathrm{Hg}$ negative pressure and was calculated as the longest $R R$ interval minus the basic $R R$ interval divided by $40 \mathrm{~mm} \mathrm{Hg}$. ${ }^{11}$

STATISTICAL ANALYSIS

The results are expressed as mean (SD). Differences between various procedures were tested by the paired Student's $t$ test. A p value $<0.05$ was regarded as significant.

\section{Results}

Table 2 shows the responses to manual carotid

Table 2 Responses to manual carotid pressure and neck suction before administration of propranolol

\begin{tabular}{|c|c|c|c|c|c|}
\hline Subject & $\max _{(\mathrm{s})} R R I$ & $\max _{(s)} R R 2$ & $\underset{(s)}{C C S I I}$ & $\underset{(s)}{\operatorname{CCSI2}}$ & $\begin{array}{l}\operatorname{RRip}_{(\mathrm{ms} / \mathrm{mm} \mathrm{Hg})} \\
\end{array}$ \\
\hline \multicolumn{6}{|c|}{ Supine position } \\
\hline $\begin{array}{l}1 \\
2 \\
3 \\
4 \\
5 \\
6 \\
7 \\
8 \\
9\end{array}$ & $\begin{array}{l}1.25 \\
1.53 \\
1.56 \\
1.82 \\
1.48 \\
2.70 \\
6.96 \\
3.82 \\
1.34\end{array}$ & $\begin{array}{l}2 \cdot 20 \\
4.90 \\
1 \cdot 42 \\
1 \cdot 80 \\
2 \cdot 62 \\
1 \cdot 78 \\
4 \cdot 78 \\
5 \cdot 50 \\
1 \cdot 14\end{array}$ & $\begin{array}{l}0.41 \\
0.61 \\
0.59 \\
0.67 \\
0.38 \\
1.60 \\
5.60 \\
2.64 \\
0.34\end{array}$ & $\begin{array}{l}1 \cdot 34 \\
4 \cdot 08 \\
0.54 \\
0 \cdot 64 \\
1 \cdot 72 \\
0 \cdot 76 \\
3 \cdot 86 \\
4 \cdot 26 \\
0.24\end{array}$ & $\begin{array}{r}4 \cdot 75 \\
4 \cdot 25 \\
3 \cdot 50 \\
6 \cdot 25 \\
8 \cdot 00 \\
6 \cdot 00 \\
12 \cdot 00 \\
18 \cdot 00 \\
3 \cdot 00\end{array}$ \\
\hline mean $(\mathrm{SD})$ & $2.50(1.87)$ & $2.90(1.70)$ & $1.43(1.74)$ & $2 \cdot 11(1.68)$ & $7 \cdot 31(4 \cdot 86)$ \\
\hline \multicolumn{6}{|c|}{ Head up tilt } \\
\hline $\begin{array}{l}1 \\
2 \\
3 \\
4 \\
5 \\
6 \\
7 \\
8 \\
9\end{array}$ & $\begin{array}{l}1.01 \\
0.80 \\
1.53 \\
1.54 \\
1.36 \\
1.92 \\
6.96^{\star} \\
3.20 \\
1.12\end{array}$ & $\begin{array}{l}1.04 \\
5.62^{\star} \\
3.84 \\
1.30 \\
1.68 \\
1.80 \\
3.08 \\
3.10 \\
0.78\end{array}$ & $\begin{array}{l}0.24 \\
0.12 \\
0.62 \\
0.75 \\
0.50 \\
1.10 \\
6 \cdot 18 \\
2 \cdot 32 \\
0.22\end{array}$ & $\begin{array}{l}0 \cdot 34 \\
4 \cdot 88 \\
3 \cdot 14 \\
0 \cdot 94 \\
0 \cdot 44 \\
0 \cdot 74 \\
2 \cdot 46 \\
2 \cdot 32 \\
0 \cdot 10\end{array}$ & $\begin{array}{r}3.50 \\
4.50 \\
1 \cdot 25 \\
2.00 \\
7.00 \\
8 \cdot 00 \\
4 \cdot 00 \\
10 \cdot 00 \\
5.50\end{array}$ \\
\hline $\operatorname{mean}(\mathrm{SD})$ & $2 \cdot 16(1.93)$ & $2.47(1.58)$ & $1.34(1.94)$ & $1.53(1.62)$ & $5.08(2.85)$ \\
\hline
\end{tabular}

max RR, maximum RR interval; CCSI, corrected carotid sinus inhibition time; RRip, RR interval prolongation during neck suction; 1 , first investigation; 2 , second investigation.

ॠVertigo. 
Table 3 Responses to manual carotid pressure and neck suction after administration of propranolol

\begin{tabular}{|c|c|c|c|c|c|}
\hline Subject & $\max _{(s)} R R I$ & $\max _{(s)} R R 2$ & $\underset{(s)}{C C S I I}$ & $\underset{(s)}{\operatorname{CCSI2}}$ & $\begin{array}{l}R R i p \\
(\mathrm{~ms} / \mathrm{mm} \mathrm{Hg})\end{array}$ \\
\hline \multicolumn{6}{|c|}{ Supine position } \\
\hline $\begin{array}{l}1 \\
2 \\
3 \\
4 \\
5 \\
6 \\
7 \\
8 \\
9\end{array}$ & $\begin{array}{l}1 \cdot 19 \\
6 \cdot 10 \\
1 \cdot 89 \\
4 \cdot 55 \\
6 \cdot 00 \\
2 \cdot 24 \\
7 \cdot 42 \\
5 \cdot 20 \\
1 \cdot 42\end{array}$ & $\begin{array}{c}4.68 \\
7.30 \\
7.04 \\
3.06 \\
6.28 \\
2.18 \\
10.20 \dagger \\
7.52 \\
0.94\end{array}$ & $\begin{array}{l}0.24 \\
5 \cdot 15 \\
0.76 \\
3.33 \\
4.45 \\
0.94 \\
6.08 \\
3.80 \\
0.22\end{array}$ & $\begin{array}{l}3.66 \\
6 \cdot 28 \\
5 \cdot 92 \\
1 \cdot 78 \\
5 \cdot 22 \\
0 \cdot 78 \\
9 \cdot 08 \\
6 \cdot 12 \\
0 \cdot 14\end{array}$ & $\begin{array}{r}3 \cdot 25 \\
8 \cdot 50 \\
5 \cdot 50 \\
6 \cdot 75 \\
17 \cdot 50 \\
10 \cdot 25 \\
15 \cdot 50 \\
31 \cdot 00 \\
3 \cdot 00\end{array}$ \\
\hline mean (SD) & $4.00(2.34)$ & $5.47(2.98)$ & $2 \cdot 77(2 \cdot 27)$ & $4 \cdot 13(3 \cdot 10)$ & $11.25(8.95)$ \\
\hline \multicolumn{6}{|c|}{ Head up tilt } \\
\hline $\begin{array}{l}1 \\
2 \\
3 \\
4 \\
5 \\
6 \\
7 \\
8 \\
9\end{array}$ & $\begin{array}{l}1 \cdot 08 \\
6 \cdot 10 \\
2 \cdot 60 \\
4 \cdot 20 \\
6 \cdot 66 \\
2 \cdot 86 \\
7 \cdot 18 \dagger \\
1 \cdot 76 \\
1 \cdot 18\end{array}$ & $\begin{array}{l}1 \cdot 84 \\
6 \cdot 54^{\star} \\
2 \cdot 00 \\
1 \cdot 92 \\
5 \cdot 50 \\
1 \cdot 80 \\
5 \cdot 94 \\
4 \cdot 62 \\
1 \cdot 00\end{array}$ & $\begin{array}{l}0 \cdot 18 \\
5 \cdot 15 \\
1 \cdot 63 \\
3 \cdot 24 \\
5 \cdot 51 \\
1 \cdot 86 \\
5 \cdot 98 \\
0 \cdot 48 \\
0 \cdot 14\end{array}$ & $\begin{array}{l}0.98 \\
5 \cdot 54 \\
1 \cdot 10 \\
0 \cdot 78 \\
4 \cdot 56 \\
0.52 \\
5 \cdot 04 \\
3 \cdot 48 \\
0 \cdot 04\end{array}$ & $\begin{array}{r}2 \cdot 25 \\
4 \cdot 50 \\
3 \cdot 00 \\
3 \cdot 75 \\
10 \cdot 25 \\
12 \cdot 50 \\
4.50 \\
11 \cdot 00 \\
3.50\end{array}$ \\
\hline mean (SD) & $3.74(2.39)$ & $3.46(2 \cdot 15)$ & $2.69(2.36)$ & $2.62(2 \cdot 27)$ & $6.14(3.94)$ \\
\hline
\end{tabular}

See footnote to table 2 for abbreviations.

*Vertigo. †Syncope.

pressure and to the negative pressure applied with the neck suction device before administration of propranolol and table 3 shows the responses after propranolol. No fall in blood pressure independent of heart rate was noted. Syncope or dizziness occurred in two men (2 and 7). None of the men developed any cardiac symptoms during a median follow up of 15 months (range 7-20) from the first investigation.

As the first investigation, during manual carotid pressure two subjects had $R R$ intervals of $>3$ s (3.8$7.0 \mathrm{~s})$ before propranolol and five (4.6-7.4 s) after propranolol administration. At the second investigation three subjects had $R R$ intervals of $>3 \mathrm{~s}$ (4.8$5.5 \mathrm{~s})$ before and seven (3.1-10.2 s) after propranolol administration (fig 1 ). The difference between the maximum RR intervals before and after administration of propranolol was statistically significant both in the supine position and with $60^{\circ}$ head up tilt $(p<0.05)$ at the first investigation, but only in the supine position ( $p=0.003)$ during the second study. In the supine position there was a statistically significant difference between the corrected carotid sinus inhibition time before and after propranolol administration at both the first and second investigation ( $p=0.034$ and $p=0.003$ respectively). Maximum lengthening of the $R R$ interval during neck suction was $>10 \mathrm{~ms} / \mathrm{mm} \mathrm{Hg}$ negative pressure in two subjects $(12-18 \mathrm{~ms} / \mathrm{mmHg}$ ) before and in fou溇 subjects $(10-31 \mathrm{~ms} / \mathrm{mm} \mathbf{~ H g})$ after propranolo administration. The difference in the lengthening of the $R R$ interval both before and after administratiog of propranolol was statistically significant ( $p=$ 0.017 ) in the supine position (fig 2).

Responses to manual pressure, expressed as corrected carotid sinus inhibition time, were sig nificantly different in the head up tilt and the supine positions, only after propranolol administration durs ing the second investigation $(p=0.006)$. During neck suction the prolongation of the $R R$ interval was significantly longer in the supine position than in the head up tilt position after propranolol administration $(p=0.027)$. There was a good correlation betweet the corrected carotid sinus inhibition time during. manual carotid pressure measured in the supino position and in the head up tilt on the two occasions both before and after propranolol administration (the four $r$ values ranged from 0.66 to $0.99 ; p<0.05$ (fig 3). A similar correlation was found during neck suction ( $r$ values 0.61 and $0.69 ; p<0.05$ ).

Lengthening of the $R R$ interval during necto suction only correlated with corrected carotid sinus inhibition time when measured in the supine positio $(r=0.67, p=0.023)$ before propranolol adminis tration. Comparison of the corrected carotid sinus inhibition times measured on two occasions showed 

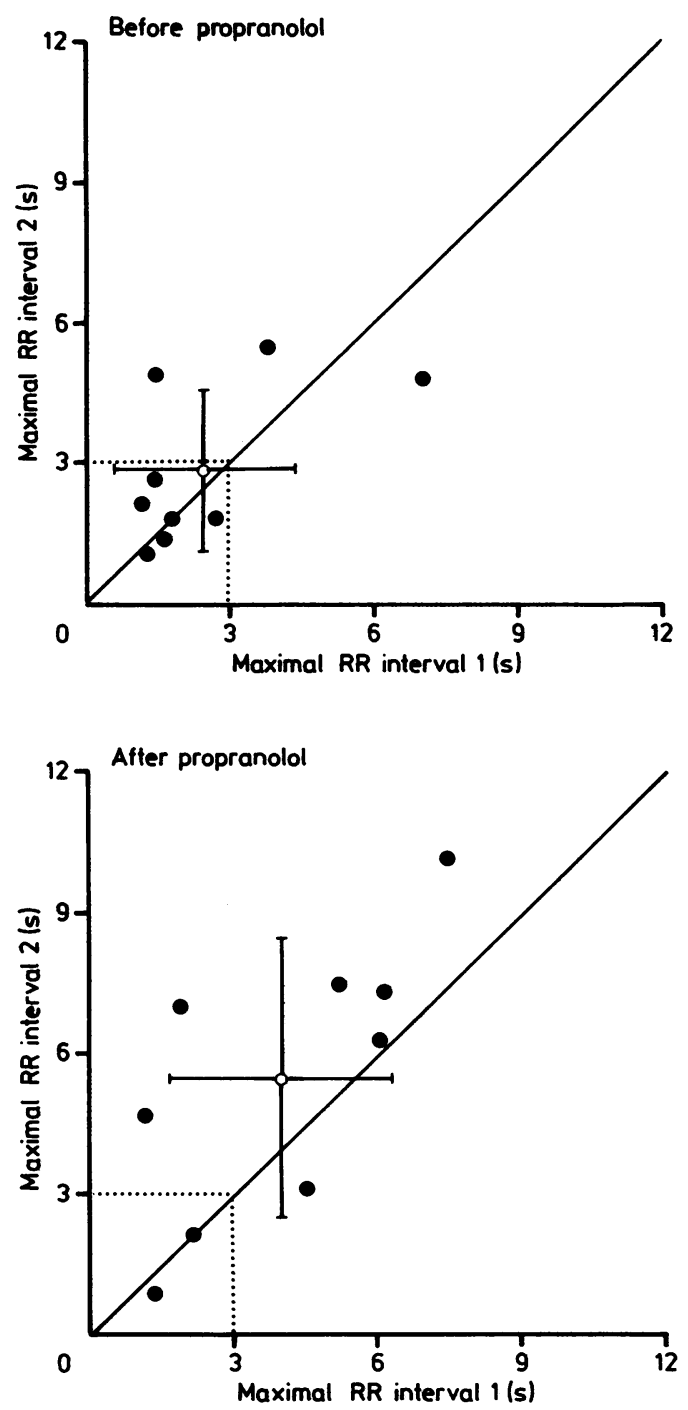

Fig 1 Maximum $R R$ intervals during manual carotid pressure in the supine position before and after propranolol administration. Individual values, means, and standard deviations are given. The differences between results before and after propranolol administration are significant. First investigation (1) $p=0.025$ and second investigation (2) $p=0.003$.

correlation only after propranolol administration (supine position: $\mathrm{r}=0.71, \mathrm{p}=0.016$; head up tilt: $r=0.77 ; p=0.008)$.

\section{Discussion}

The association between hypersensitivity to the

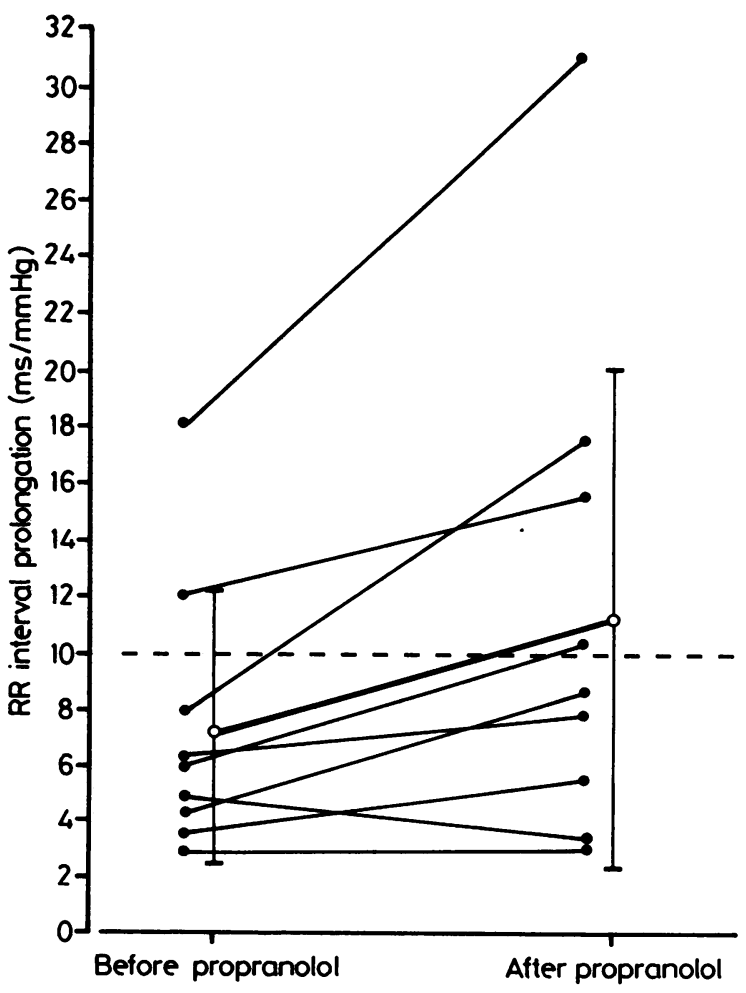

Fig 2 Prolongation of the $R R$ interval during neck suction. Individual values, means, and standard deviations are given $(p=0.017)$.

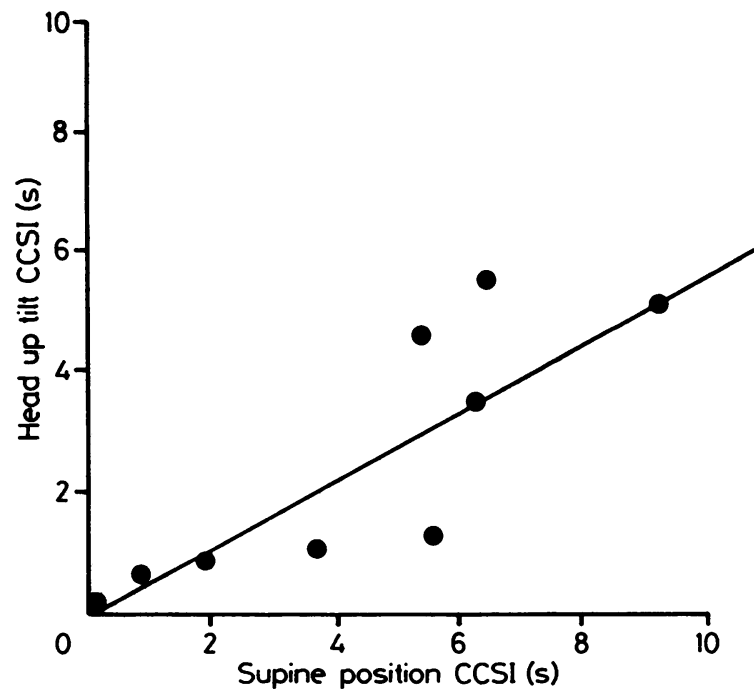

Fig 3 Correlation between corrected carotid sinus inhibition time (CCSI) in the supine position and during head up tilt at the second investigation after propranolol administration $(r=0.82 ; p=0.004)$. 
carotid sinus reflex and spontaneous syncope has long been recognised. ${ }^{1}$ The introduction of pacemaker treatment, with excellent results in patients with the cardio-inhibitory form of the carotid sinus syndrome, has evoked new interest in this condition. ${ }^{12}{ }^{13}$ Carotid sinus hypersensitivity in combination with unexplained syncope is a widely accepted indication for pacemaker treatment. The number of patients diagnosed as having carotid sinus syndrome, however, varies considerably and this syndrome accounts for between $0.5 \%$ and $12 \%$ of all pacemaker implantations in different reports. ${ }^{14}$ These differences probably reflect several difficulties in the evaluation of the cardiac response to carotid sinus massage. Firstly the reproducibility of carotid massage is low, ${ }^{1516}$ and secondly the symptoms vary spontaneously. ${ }^{17}$ Furthermore, a spontaneous recovery in $50 \%$ of patients with a diagnosis of carotid sinus syndrome has been reported.$^{18}$ In other studies spontaneous remission rates in syncope ranging from 67 to $100 \%$ have been found. ${ }^{19-21}$ All of a subgroup of patients with unexplained syncope recovered.

There have been few studies of the normal response to carotid massage and the results are conflicting. ${ }^{14812}$ It is difficult to establish an unequivocal diagnosis with an unphysiological test that is difficult to quantify. A more scientific test that uses an airtight neck collar to apply a negative pressure has therefore been suggested. When the RR interval is prolonged by more than $10 \mathrm{~ms} / \mathrm{mm} \mathrm{Hg}$ negative pressure the response is regarded as abnormal. ${ }^{11}$

We used both manual pressure on the carotid sinus and a neck suction device in our study. Carotid pressure was applied according to recent recommendations. ${ }^{3}$ To minimise variations in the technique the same person always applied the carotid pressure. Hypersensitivity of the carotid sinus was noted in three apparently healthy subjects, a finding that casts doubt on the claim that the current manual carotid test discriminates between normal and abnormal responses. ${ }^{37}$ We would have to follow up these three patients for several years to find out whether their results should be regarded as normal or as indicating a pre-symptomatic phase. If the explanation for the discrepancy between our results and those of other investigations lies in differences in technique, this is further evidence for difficulties in standardising carotid massage. In addition, the comparison between the results obtained on two different occasions confirms previous reports that the reproducibility of the carotid test is low. Application of the suggested criterion for an abnormal response during neck suction to our patients reduced the number of abnormal responders to two. ${ }^{11}$ Our results do not detract from the evidence of an association between syncope and carotid sinus hypersensitivity, but because we found positive tests in a significan number of apparently healthy individuals, abnormas? test results should not automatically lead to active treatment.

There was a good correlation between the correc $\frac{\bar{m}}{\bar{D}}$ ted carotid sinus inhibition time in the supine position and with head up tilting during all six tes® periods in our study. This indicates that stimulation of the carotid sinus was consistent. After administra $=$ tion of propranolol the results were considerably $\vec{\omega}$ different. $R R$ intervals of more than $3 \mathrm{~s}$ were noted in seven men and four showed an abnormal response tọ neck suction. One of these four men respondeक normally to the manual carotid test. But others foun $\phi$ that intravenous administration of a $\beta$ blocker did nof enhance the response to carotid massage in patients with carotid sinus hypersensitivity. ${ }^{22}$

If we assume consistent stimulation of the carotid sinus throughout our study, our results suggest tha alteration of the sympathetic response may be res ponsible for lengthening of the RR interval. Thi suggestion accords with the lack of difference bet $\stackrel{D}{-}$ ween the degree of $R R$ prolongation before and afte $\overrightarrow{0}$ $\beta$ blockade in patients with carotid sinus hypersen $\infty^{\circ}$ sitivity. ${ }^{22}$

Little is known about the influence of $\beta$ blockadę on autonomic sympathetic activity, and differen groups of neurons respond differently. Administra tion of metoprolol increased sympathetic activity iro muscle. ${ }^{23}$ Earlier studies showed considerable buf transient sympathetic responses in the muscles $t \vec{\Phi}$ changing levels in afferent baroreceptor impulses. ${ }^{24} 25$ During alternating high and low neck suction an increase in suction inhibited sympathetic outflow and a fast onset of neck suction led to short term totad inhibition of sympathetic activity. These interesting findings suggest a highly speculative explanation fo the considerable lengthening of the RR interval after. administration of propranolol-a result thaô simulated hypersensitivity of the carotid sinus? Blockade of the $\beta$ receptors might increase sympath etic outflow, possibly with a concomitant increase of parasympathetic activity. In this situation a suddern. withdrawal of the sympathetic nerve activity to the heart might lengthen the RR interval.

In conclusion, three of nine apparently health elderly men showed carotid sinus hypersensitivity- $-\infty$ that is RR intervals of more than three second during carotid sinus massage or lengthening of the $\mathrm{RR}$ interval by more than $10 \mathrm{~ms} / \mathrm{mm} \mathrm{Hg}$ during neck suction. After $\beta$ blockade seven of the nine ment showed carotid sinus hypersensitivity. This suggests that an alteration in sympathetic nerve activity ma be responsible for the physiological mechanisms tha? cause prolonged $R R$ intervals. Whatever the true 
explanation for these results, they indicate that a positive test for carotid sinus sensitivity-should not automatically prompt active treatment.

This work was supported by the Swedish Heart Foundation and the Karolinska Institute.

\section{References}

1 Weiss $\mathrm{S}$, Baker J. The carotid sinus reflex in health and disease. Medicine (Baltimore) 1933;12:297-354.

2 Leatham A. Carotid sinus syncope. Br Heart $J$ 1982;47:409-10.

3 Morley CA, Sutton R. Carotid sinus syncope. Int J Cardiol 1984;6:287-93.

4 Sigler LH. The response to carotid sinus pressure at various ages and heart rates and rhythms. $\mathrm{Am} \mathrm{J} \mathrm{Med}$ Sci 1933;186:118-24.

5 Heidorn GH, McNamara AP. Effect of carotid sinus stimulation on the electrocardiograms of clinically normal individuals. Circulation 1956;14:1104-13.

6 Smiddy J, Lewis HD, Dunn M. The effect of carotid massage in older men. J Gerontol 1972;27:209-11.

7 Hudson WM, Morley CA, Perrins EJ, Sutton R. Is a hypertensive carotid sinus reflex relevant? [Abstract] $P A C E$ 1983;6:A18.

8 Jonsell S. A method for the determination of the heart size by teleroentgenography (a heart volume index). Acta Radiol (Stockholm) 1939;29:325-40.

9 Ludbrook J, Mancia G, Ferrari A, Zanchetti A. The variable-pressure neck-chamber method for studying the carotid baroreflex in man. Clin Sci Mol Med 1977;53:165-71.

10 Eckberg DL, Cavanagh MS, Mark AL, Abboud FM. A simplified neck suction device for activation of carotid baroreceptors. J Lab Clin Med 1975;85:167-73.

11 Dehn TCB, Morley CA, Sutton R. A scientific evaluation of the carotid sinus syndrome. Cardiovasc Res 1984;18:746-51.

12 Davies AB, Stephens MR, Davies AG. Carotid sinus hypersensitivity in patients presenting with syncope. Br Heart J 1979;42:583-6.

13 Morley CA, Perrins EJ, Grant P, Chan SL, McBrien DJ, Sutton R. Carotid sinus syncope treated by pacing. Analysis of persistent symptoms and role of atrioventricular sequential pacing. $\mathrm{Br}$ Heart $J$ 1982;47:411-8.

14 Feruglio GA, Sternotti G, Proclemer A, Mirolo R. Diagnostic reappraisal of 35 patients pacing for 3-6 years for carotid sinus syndrome [Abstract]. PACE 1983;6:A18.

15 Podczek A, Frohner K, Meisl F, Unger G, Steinbach K. Effect of carotid sinus massage (CSM) on blood pressure (BP) in patients (pts) with carotid sinus syndrome [Abstract]. PACE 1983;6:A17.

16 Podczek A, Frohner K, Meisl F, Unger G, Steinbach K. Significance of carotid sinus massage (CSM) in patients (pt) with cerebrovascular symptoms (CVS) [Abstract]. PACE 1983;6:A17.

17 Walter PF, Crawley IS, Dorney ER. Carotid sinus hypersensitivity and syncope. Am J Cardiol 1978;42:396-403.

18 Blanc JJ, Penther Ph. Carotid sinus hypersensitivity (CSH); natural history in 33 patients [Abstract). PACE 1983;6:A17.

19 Morady F, Shen E, Schwartz A, et al. Long-term follow-up of patients with recurrent unexplained syncope evaluated by electrophysiologic testing. $\mathrm{J} \mathrm{Am}$ Coll Cardiol 1983;2:1053-9.

20 Dhingra RC, Denes P, Wu D, et al. Syncope in patients with chronic bifascicular block. Ann Intern Med 1974;81:302-6.

21 Doherty JU, Pembrook-Rogers D, Grogan EW, et al. Electrophysiologic evaluation and follow-up characteristics of patients with recurrent unexplained syncope and presyncope. Am J Cardiol 1985;55:703-8.

22 Rauh GF, Bachmann KF. Acute and chronic treatment with betablockers in patients with hypersensitive carotid sinus reflex (HSCR) [Abstract]. $X$ World Congress of Cardiology, Washington DC, 14-19 September 1986. Clinical electrophysiology and pharmacology $p 163$.

23 Sundlöf G, Wallin BG, Strömgren E, Nerhed C. Acute effects of metoprolol on muscle sympathetic activity in hypertensive humans. Hypertension 1983; 5:749-56.

24 Wallin BG, Eckberg DL. Sympathetic transients caused by abrupt alterations of carotid baroreceptor activity in humans. Am J Physiol 1982;242:H185-90.

25 Båth E, Lindblad LE, Wallin BG. Effects of dynamic and static neck suction on muscle sympathetic activity. J Physiol 1981;311:551-64. 